\title{
SARS-CoV-2 Detection Using Reverse Transcription Strand Invasion Based Amplification And A Portable Compact Size Instrument
}

Maiken Worsøe Rosenstierne ( $\sim$ Mwr@egoo.health )

Qlife Aps

Shreya Joshi

Qlife Aps

E. Thomas Danielsen

Qlife Aps

Helen Webb

Qlife Aps

Dac Mui Luong

Qlife Aps

Julie Bjerring

Qlife Aps

Julie Hindkær

Qlife Aps

Lærke Jørgensen

Qlife Aps

Julie Blauenfeldt

Qlife Aps

Ask Bojesen

Qlife Aps

Flemming Holck

Qlife Aps

Johnny Lau

Qlife Aps

Lars Bangsgaard

Qlife Aps

Jacob Lind

Qlife Aps

Mette Dragheim

Qlife Aps

Mikkel Jacobsen 
Qlife Aps

Robert Elkær

Qlife Aps

Steven Clauwaert

Qlife Aps

Kristina Christensen

Qlife Aps

Charlotta Polacek

Statens Serum Institut

Anders Fomsgaard

Statens Serum Institut

Tuomas Ojalehto

Aidian

Antti Tullila

Aidian

Mirko Brummer

Aidian

Claus Antonio Juel Jensen

Nordsjællands Hospital

Frederikke Holm Jensen

Hvidovre Hospital

Uffe Vest Schneider

Hvidovre Hospital

Jan Gorm Lisby

Hvidovre Hospital

Rikke Lind Jørgensen

Hvidovre Hospital

Thomas Warthoe

Qlife Aps

Ebbe Finding

Qlife Aps

Peter Warthoe

Qlife Aps

Research Article

Keywords: SARS-CoV-2, COVID-19, SIBA, POCT, NAAT

Posted Date: July 14th, 2021 
DOI: https://doi.org/10.21203/rs.3.rs-654239/v1

License: @ (i) This work is licensed under a Creative Commons Attribution 4.0 International License. Read Full License

Version of Record: A version of this preprint was published at Scientific Reports on November 15th, 2021. See the published version at https://doi.org/10.1038/s41598-021-01744-y. 


\section{Abstract}

Rapid nucleic-acid based tests that can be performed by non-professionals outside laboratory settings could help the containment of the pandemic SARS-CoV-2 virus and may potentially prevent further widespread lockdowns. Here, we present a novel compact portable detection instrument (the Egoo Health System) for extraction-free detection of SARS-CoV-2 using isothermal Reverse Transcription Strand Invasion Based Amplification (RT-SIBA). The SARS-CoV-2 RT-SIBA assay can be performed directly on crude oropharyngeal swabs without nucleic acid extraction with a reaction time of 30 minutes. The Egoo health system uses a capsule system, which is automatically sealed tight in the Egoo instrument after applying the sample, resulting in a closed system optimal for molecular isothermal amplification. The performance of the Egoo Health System is comparable to the PCR instrument with an analytical sensitivity of 25 viral RNA copies per SARS-CoV-2 RT-SIBA reaction and a clinical sensitivity and specificity between $87.0-98.4 \%$ and $96.6-98.2 \%$ respectively.

\section{Introduction}

Severe acute respiratory syndrome coronavirus 2 (SARS-CoV-2), which causes coronavirus disease 2019 (COVID-19), emerged in Wuhan, China in December 2019 and became a worldwide pandemic in March $2020^{1}$. To this date (15th of June 2021), there has been a total of $175,847,347$ confirmed COVID-19 cases and 3,807,276 deaths worldwide (https://covid19.who.int/). The COVID-19 pandemic has become a global crisis, impacting both global health and economy. The return to normality in daily life largely depends on identifying infected individuals, encouraging isolation and quarantine, and development of vaccines against the virus. To this date $2,187,874,534$ vaccine doses have been administered (https://covid19.who.int/) but there is still a huge demand for COVID-19 testing and many countries are screening their population for the presence of the virus using RT-PCR and antigen tests ${ }^{2-4}$. RT-PCR is the gold standard nucleic acids amplification test (NAAT) for diagnosis of COVID-19 and many other viral infections due to the high sensitivity and specificity of the method. However, the method is labour intensive, time-consuming (typically $>4$ hours), and requires transport to laboratories with specialized laboratory equipment and personnel, which can prolong the time to result up to 24 hours or longer. This extended turnaround time has pushed the development of simplified NAAT tests that can be performed locally. Simplified RT-PCR workflows has been developed using nucleic acid (NA) extraction free methods such as direct lysis or heat ${ }^{5-9}$ or alternative NAAT tests such as loop-mediated isothermal amplification (RT-LAMP) ${ }^{10-17}$, CRISPR-Cas 12 and CRISPR-Cas13a based systems ${ }^{18,19}$, recombinase polymerase amplification (RT-RPA) ${ }^{20-22}$, and nicking-endonuclease amplification reactions (RT-NEAR) ${ }^{23,24}$ which can reduce the overall reaction time to approximately 20-30 minutes. However only a few of these NAAT tests can be performed outside specialized laboratories such as the Cue COVID-2 test ${ }^{25}$, the Visby medical SARS-CoV-2 test ${ }^{26}$ and the DNAnudge Covid- 19 test ${ }^{27}$.

Here we present a new compact size portable point of care (POC) system called the Egoo Health System, which consists of an Egoo instrument (470 g), an Egoo clinical application (app), and an Egoo assay 
capsule. The Egoo Health System was initially designed for detection of biomarkers in blood, saliva and urine, but here we show that the Egoo Health System can also be used to detect SARS-CoV-2 from oropharyngeal. The compact size Egoo instrument is designed for use with multiple assay types, each utilizing a single-use, test specific assay capsule, thus the Egoo Health System can be used for several different assays, including both biochemical and NAAT tests. After an assay run, raw data is sent via WiFi to the Egoo server for raw data analysis, and the calculated assay result is sent to a laptop/smartphone, which is the primary display for the Egoo Health System. The Egoo Health System was initially developed for use in private homes but can also be used in primary care clinics, nursing homes, and workplaces, without the need of specialized laboratory staff.

We have developed an isothermal SARS-CoV-2 molecular assay for the Egoo Health system based on Reverse Transcription Strand Invasion Based Amplification (RT-SIBA) ${ }^{28,29}$ and SYBR green detection. The SARS-CoV-2 RT-SIBA assay can be performed directly on crude oropharyngeal swabs without NA extraction with reaction time of 30 minutes. The SARS-CoV-2 RT-SIBA assay can also be performed in a high-throughput format using PCR instruments using specialized laboratory personnel. The SARS-CoV-2 RT-SIBA assay performed on the compact size Egoo instrument is as sensitive and specific, as when performed on a PCR instrument, with an analytical sensitivity of 25 viral RNA copies per reaction and a clinical sensitivity and specificity of $87.0-98.4 \%$ and $96.6-98.2 \%$ respectively when compared to different reference SARS-CoV-2 RT-PCR assays and platforms.

\section{Methods}

\section{Ethical statement}

The study is not a medical health science research project but a method comparison study using surplus material from routine oropharyngeal samples collected at Nordsjællands hospital and Amager and Hvidovre University hospital. The need for informed consent and ethical approval were reviewed by the Institutional Review Board at Amager and Hvidovre University Hospital and Nordsjællands hospital and the regional research ethic committee for Region Hovedstaden (The National Committee on Health Research Ethics, Region Hovedstaden, Blegdamsvej 60, 1. Sal opgang 94A11, DK-2100 Copenhagen) and found not to need approval according to national ethic research regulation.

\section{The Egoo Health System}

The Egoo Health System comprises of an Egoo instrument (capsule reader), an Egoo power adaptor, an Egoo clinical application (app), and an Egoo assay capsule. The Egoo instrument is compact in size (W66 x H107 x D94 mm), and weight (470 g/1.04 lbs). It consists of an integrated optical microelectromechanical system (optical MOEM) ${ }^{30}$ and has a dual optical unit for simultaneously measuring fluorescence and absorbance (Table 1). The optical unit is integrated on a micro heating (max. $\left.50^{\circ} \mathrm{C}\left(122^{\circ} \mathrm{F}\right)\right)$ and vortex mixing unit (max. $\left.3000 \mathrm{rpm}\right)$ for heating and mixing the assay reagents during assay runs. The Egoo instrument has a mechanical piston mechanism which via a plunger unit can 
tightly seal the Egoo assay capsule after applying the sample, resulting in a closed system. In addition, the piston mechanism can inject various reagents from the integrated capsule injection chambers which sit on top of each assay specific Egoo capsule. The SARS-CoV-2 RT-SIBA Egoo capsule (W24 x H28 x D36 $\mathrm{mm}$ ) (Table 2) consists of $140 \mu$ frozen SARS-CoV-2 RT-SIBA Mastermix. The SARS-CoV-2 RT-SIBA Egoo capsules are stored at $-20^{\circ} \mathrm{C}$ until their intended use.

\section{Egoo data analysis}

After each assay run, the raw data is sent via WiFi to the Egoo server for raw data analysis. For the SARSCoV-2 RT-SIBA assay, the calculations are based on 3 fluorescence measurements recorded every minute for 30 minutes. The fluorescence measurements are graphed via an algorithm within the server. Based on an initial data set of $>100$ positive/negative oropharyngeal patient samples used to define minimum and maximum values within the algorithm (data not shown), the assay result is determined. The primary display for the Egoo Health System is a laptop/smartphone. Based on the accumulated curve and slope, the assay result is reported as either "negative", "positive" or "inconclusive" to the end user. Alternatively, the raw data can be analysed via Excel or other graphing programs, should the end user wish to visualize the resulting amplification curve from the reaction.

\section{Sample preparations and dilutions}

Oropharyngeal swabs collected with flocked swabs (Jiangsu Hanheng Medical Technology, Copan) from patients were dissolved directly into either $1 \mathrm{ml}$ SIBA lysis/reaction buffer (Aidian/Qlife), $1 \mathrm{ml}$ PBS (Gibco), $1 \mathrm{ml}$ Universal Transport Media (UTM) (Copan), $1 \mathrm{ml}$ Virus Transport Media (VTM) (NEST Biotechnology) or $1 \mathrm{ml}$ VTM (Mole Bioscience). To release virus from the flocked swabs and the sample collection tubes were incubated for 10 minutes at room temperature. Samples dissolved in PBS, UTM, VTM or antigen buffers (GenSure ${ }^{\text {TM }}$ COVID-19 Antigen Rapid Test, ACRO Rapid Test, BIOSYNEX ${ }^{\circ}$ COVID-19 Ag BSS, COVID-19 Ag (SD Biosensor)) were diluted 10-fold in SIBA lysis/reaction buffer (containing mild detergents and $80 \mathrm{mM} \mathrm{Mg-acetate)} \mathrm{before} \mathrm{being} \mathrm{applied} \mathrm{to} \mathrm{the} \mathrm{SARS-CoV-2} \mathrm{RT-SIBA} \mathrm{Mastermix} \mathrm{(Qlife).}$ Samples undergoing SARS-CoV-2 testing by RT-PCR on the BGI system at Hvidovre Hospital or the Corbas Liat System at Nordsjællands Hospital were used without further preparation. Purification of total NA in the BGI system was done on a MGISP-960 using the MGIEasy Magnetic Beads Virus DNA/RNA Extraction Kit (MGI Tech Co., Ltd.). The sample extraction amount was $180 \mu \mathrm{l}$ and total NA was eluted in $33 \mu \mathrm{l}$.

\section{SARS-COV-2 RT-SIBA}

The SARS-CoV-2 RT-SIBA Mastermix (Qlife) consists of mixing three reagents according to the following protocol. The RT-SIBA Mix A, Mix B and Oligomix were thawed on ice and mixed by vortexing. Mix A can in some instances form precipitates which can be re-dissolved by heating to $37-41^{\circ} \mathrm{C}$ followed by vortexing. For reactions performed in a PCR instrument the mastermix was prepared by mixing $7 \mu \mathrm{l}$ Mix A, $7 \mu \mathrm{l} \mathrm{Mix} \mathrm{B}$, and $3.5 \mu \mathrm{l}$ Oligomix per reaction. Mastermix $(17.5 \mu \mathrm{l})$ was added to PCR tubes and $2.5 \mu \mathrm{l}$ of sample (diluted 10-fold in SIBA lysis/reaction buffer) was added to the mastermix. The RT-SIBA reactions were performed using either the MX3005P (Stratagene) or CFX96 (BioRAD) PCR instrument. Fluorescence 
measurements were recorded every minute for 30 minutes at $44^{\circ} \mathrm{C}$, followed by a melt curve analysis: $44^{\circ} \mathrm{C}-95^{\circ} \mathrm{C}$. For reactions performed in the Egoo device, Egoo capsules (Qlife) containing $140 \mu \mathrm{l}$ of premade mastermix were thawed and loaded into the Egoo device after applying $20 \mu \mathrm{l}$ of the sample (diluted 10-fold in SIBA lysis/reaction buffer). Before the reaction starts, the Egoo capsule is closed in the Egoo instrument once the piston mechanism seals the capsule with the plunger. Once the plunger has sealed the capsule tight, the Egoo instrument heats the capsule to $44^{\circ} \mathrm{C}$ for 30 minutes. During the reaction, the reagents within the capsule are mixed by vortexing (1000 rpm) for 3 seconds every 5 minutes. Fluorescence measurements are recorded 3 times every minute.

\section{SARS-CoV-2 RT-PCR}

The E-gene assay from Charité Berlin ${ }^{31}$ was used with the Luna ${ }^{\circledR}$ Universal Probe One-Step RT-qPCR Kit

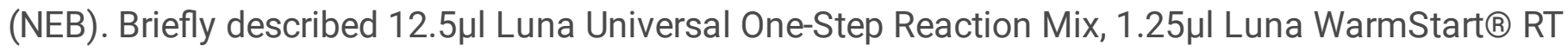

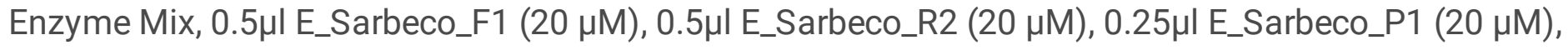
$7.5 \mu \mathrm{l}$ nuclease-free water and $2.5 \mu \mathrm{l}$ sample (purified RNA or sample diluted 10-fold in SIBA lysis/reaction buffer) were mixed and run with the following program: $10 \mathrm{~min}$ at $55^{\circ} \mathrm{C}, 3 \mathrm{~min}$ at $95^{\circ} \mathrm{C}, 45$ cycles of $15 \mathrm{sec}$. at $95^{\circ} \mathrm{C}$ and $30 \mathrm{sec}$. at $58^{\circ} \mathrm{C}$. The RT-PCR reactions were performed using either the MX3005P (Strategene), CFX96 (BioRAD), or AriaMx (Agilent), and fluorescence were captured using the FAM channel. At Nordsjællands hospital the Cobas SARS-CoV-2 \& Influenza A/B NAAT test on the Cobas Liat System (Roche) was used directly $(200 \mu \mathrm{l})$ in the cartridge according to the manufactures instructions. At Hvidovre Hospital a newly laboratory developed test adopted from ${ }^{32}$ targeting the E-gene and the N2-gene in SARS-CoV-2 and RNaseP as human target was used for RT-PCR analysis in the BGI system. Reactions were set up in a $20 \mu \mathrm{l}$ reaction volume using $8 \mu \mathrm{L}$ sample (purified RNA), $10 \mu \mathrm{l} \mathrm{KiCqStart} \mathrm{One-Step} \mathrm{Probe}$ RT-qPCR ReadyMix (Sigma-Aldrich), $1 \mu \mathrm{l} 4 \mathrm{mM}$ dUTP (0.2 $\mathrm{mM}$ in total) and $1 \mu \mathrm{lmix}$ of primers and probes. Final concentrations of primers and probes were $500 \mathrm{nM}$ CoV_E_F primer (5'ACAGGTACGTTAATAGTTAATAGCGT-3'), 400 nM CoV_E_R primer (5'- ATATTGCAGCAGTACGCACACA-3'), 150 nM CoV_E_P probe (5'-LC610- ACACTAGCCATCCTTACTGCGCTTCG-BBQ-3'), 400 nM CoV_N2_F primer (5'- TTACAAACATTGGCCGCAAA-3'), 400 nM CoV_N2_R1 primer (5'- AAGGTGTGACTTCCATGCCA3'), 150 nM CoV_N2_P FAM probe (5'-FAM- ACAATTTGCCCCCAGCGCTTCAG-BBQ-3'), 100 nM RNaseP_F primer (5'-AGATTTGGACCTGCGAGCG-3'), 100 nM RNaseP_R primer (5'- GAGCGGCTGTCTCCACAAGT-3') and 125 nM RNaseP_P_Cy5 probe (5'-Cy5- TTCTGACCTGAAGGCTCTGCGCG-BBQ-3'). RT-PCR was

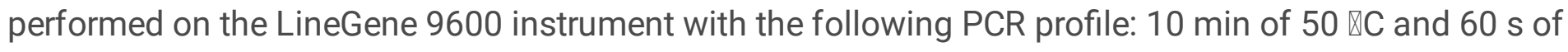
$95 \otimes C$ followed by 45 cycles of $95 \otimes C$ for $5 s$ and $60 \otimes C$ for $30 s$.

\section{Virus culture and RNA purification}

Inactivated virus cultures for Epstein-Barr Virus (EBV)(B95-8), Parainfluenza virus type 1 (PIV-1), Adenovirus type 5 (Adv5), Respiratory Syncytial virus type A (RSV-A)(2006), Influenza A (H1N1pdm), (INFL A)(NY/02/07), Influenza A (H3N2), Influenza B (INFL B)(Yamagata/16/88), Rhinovirus A16, Enterovirus type 68 (EV-68)(2007), Human metapneumovirus (hMPV) (Peru2-2002), Coronavirus 0C43, Coronavirs NL63, Coronavirus 229E, SARS-COV-2 (Italy-INMI1)(1.02 x $10^{8}$ TCID $_{50} / \mathrm{mL}$ ), SARS-COV-2 (USA- 
WA1/2020)(3.09 $\left.\times 10^{8} \mathrm{TCID}_{50} / \mathrm{ml}\right)$, SARS-COV-2 (Hong Kong/VM2000i06i/2020) $\left(1.15 \times 10^{7} \mathrm{TCID}_{50} / \mathrm{mL}\right.$ ) purchased from Helvetica Health Care were used directly by spiking into an oropharyngeal swab background resulting in a 10-fold dilution of the virus. QCMD panels for MERS (2019), RSV (2019), hMPV (2019) and coronavirus (2019) were purified using the MagNA Pure 96 system (Roche) and the DNA and Viral NA Small Volume Kit (Roche). The human SARS-CoV-2 isolate 2019-nCoV Munchen 1-2 2020/984 (026V-03883, EVAg) was cultured in VERO E6 cells, and the virus titre of the supernatant was determined to $1.6 \times 10^{7} \mathrm{TCID}_{50} / \mathrm{ml}$. In addition, the harvested supernatant was quantified to $1.2 \times 10^{7} \mathrm{RNA}$ copies $/ \mathrm{ml}$ using MagNA Pure purified RNA and a standard curve based on the synthetic SARS-CoV-2 RNA control (MT007544.1, Twist Bioscience) spiked into RNA from a SARS-CoV-2 negative oropharyngeal swab. The quantification was performed using the RT-PCR E-gene assay ${ }^{31}$.

\section{Clinical samples}

Retrospective SARS-CoV-2 positive and negative oropharyngeal patient samples were used to analyse the clinical sensitivity of the SARS-CoV-2 RT-SIBA assay using the Egoo instrument. 227 oropharyngeal swabs dissolved in PBS and diagnosed positive or negative for SARS-CoV-2 using direct lysis and the Egene RT-PCR assay ${ }^{31}$ from the Qlife COVID-19 Service Center were analyzed. Informed patient consent was obtained for Qlife patient samples. In addition, two independent method comparison studies were performed at two different hospitals. At Hvidovre and Amager hospitals, 700 retrospective oropharyngeal swabs dissolved in UTM previously diagnosed positive or negative for SARS-CoV-2 using the SARS-CoV-2 Roche Flow/MGI-BGI RT-PCR assay were re-tested followed by analysis using the SARS-CoV-2 RT-SIBA assay on the Egoo instrument. At Nordsjællands hospital, 224 patient samples diagnosed positive or negative for SARS-CoV-2 using the SARS-CoV-2 Cobas Liat System (Roche) were re-tested within 24 hours using the SARS-CoV-2 RT-SIBA assay on the Egoo instrument. All oropharyngeal patient swabs were collected in accordance with national guidelines and regulations and only surplus material from routine oropharyngeal samples were used in this study.

\section{Results}

\section{The Egoo Health System}

The Egoo Health System consists of a small Egoo device, a laptop or mobile phone, with the Egoo clinical app, and an Egoo capsule containing the assay of interest (Fig. 1a-d). Because of the limited heating system in the Egoo device (max. $50^{\circ} \mathrm{C}$ ), we developed an isothermal SARS-CoV-2 RT-SIBA assay that target the RdRp gene in SARS-CoV-2 genome (Fig. 1e). In silico analysis of 699,737 full-length SARS-CoV2 sequences submitted to GISAID ${ }^{33}$ in the period from 26th of December 2019 to 22nd of May 2021 show that $99.63 \%$ of all worldwide isolates would be detected by the SARS-CoV-2 RT-SIBA assay including the UK (B.1.1.7), South Africa (B.1.351), Brazil (P.1) and Indian (B.1.1617.2) variants (Supplementary Table S1). For methodological simplification, the SARS-CoV-2 RT-SIBA assay was designed to be used directly on crude samples without NA extraction using SIBA lysis/reaction buffer (Fig. 1f), which contain mild detergents and magnesium. 


\section{The analytical specificity of the SARS-CoV-2 RT-SIBA assay}

First, we wanted to investigate the analytical specificity of the SARS-CoV-2 RT-SIBA assay against other human coronaviruses (hCoV-NL63, hCoV-229E and hCoV-OC43) and the most common human respiratory viruses such as Influenza A H1N1, Influenza B and Respiratory Syncytial virus (RSV) (Table 3). Purified viral NA or inactivated virus cultures from the different viruses were spiked into a SARS-CoV-2 negative oropharyngeal background. The samples were diluted 10-fold in SIBA lysis/reaction buffer before being analysed with the SARS-CoV-2 RT-SIBA assay using two different PCR instruments (MX3005P or CFX96) and the small Egoo Health system (Table 3). No cross-reactivity to other respiratory viruses was detected for either the purified NA or whole lysed virus cultures (non-purified RNA) and the SARS-CoV-2 RT-SIBA assay was $100 \%$ specific for SARS-CoV-2.

\section{The analytical sensitivity of the SARS-CoV-2 RT-SIBA assay}

Next, we wanted to test the analytical sensitivity of the SARS-CoV-2 RT-SIBA assay. Synthetic SARS-CoV-2 RNA and inactivated SARS-CoV-2 virus culture was spiked into negative oropharyngeal swab at different concentrations and diluted 10-fold in SIBA lysis/reaction buffer. The different dilutions were tested using both a PCR instrument (Mx3005P) and five different Egoo instruments (Fig. 2a-b, Table 4). Figure 2 shows the amplification curves of the synthetic SARS-CoV-2 RNA from the PCR instrument (Fig. 2a) and five different non-calibrated Egoo instruments (Fig. 2b). For the PCR instrument, the dilutions were predominantly detected with 8-16 minutes, whereas the dilutions were detected within 12-22 minutes on the different Egoo instruments (Fig. 2, Table 4). For the endpoint fluorescence signal, differences between the Egoo instruments were observed which indicated that the Egoo instruments were not calibrated, however, this did not influence the calculated results from the backend server. The limit of detection (LOD) of the SARS-CoV-2 RT-SIBA assay was found to be between 20-25 RNA copies/reaction when using both the synthetic RNA and whole virus culture. No difference between the LOD was observed between the PCR instrument and the five Egoo instruments tested (Table 4). However, for the PCR instrument only $2.5 \mu \mathrm{l}$ of sample was loaded into the PCR tube, whereas $20 \mu$ of sample was loaded into the Egoo capsule. This corresponds to a lower sample input concentration for the Egoo instrument compared to the PCR instrument. The Egoo instrument can detect as low as 1.3 viral RNA copies/ $\mu$ (Table 4).

\section{Extraction free sample handling}

The SARS-CoV-2 RT-SIBA assay was designed to be used directly on crude samples without NA extraction using a SIBA lysis/reaction buffer (Fig. 1f). To test if lysis can be performed directly in the sample collection tube, different concentrations of SARS-CoV-2 virus culture were spiked into a negative oropharyngeal swab background and subsequently added to sampling swabs $(n=16)$. SIBA lysis/reaction buffer $(500 \mu l)$ was added directly to the tubes containing the spiked swabs and the tubes were incubated for 10 min at RT with shaking to release the viral RNA from the swab, before being analysed by the SARS-CoV-2 RT-SIBA assay using a PCR instrument. As negative controls, negative oropharyngeal swabs $(n=18)$ directly dissolved SIBA lysis/reaction buffer were also analysed (Fig. 3a). Swabs spiked with 4200 viral RNA copies and dissolved in SIBA lysis/reaction buffer to a concentration 
of 79 viral RNA copies could easily be detected with the SARS-CoV-2 RT-SIBA reaction (Fig. 3a). Analysis of SARS-CoV-2 negative oropharyngeal swabs showed positive detection in $39 \%(7 / 18)$ of the samples (Fig. 3a) and analysis of the melting curve showed a second melting peak around $56^{\circ} \mathrm{C}$, whereas the correct melting peak for a SARS-CoV-2 positive sample should be at $68^{\circ} \mathrm{C}$ (Fig. 3b). The SARS-CoV-2 assay is based on a SYBR Green detection of the amplified product, and therefore any non-target amplification occurring due to the genomic background in the sample is also detected. This non-target amplification is easily distinguishable from target-specific amplification in a PCR instrument by performing melt curve analysis. Since melt curve analysis cannot be performed in the Egoo device, we investigated if diluting the samples by 2-, 5-, 10-, 20-fold would reduce non-target amplification (Fig. 3c and Fig. 3d). Dilution of the samples clearly showed that 10- and 20-fold dilutions of the samples eliminated the formation of the non-target melting peak (Fig. 3c and 3d). To further test this, 128 negative oropharyngeal patient swabs (dissolved in $1 \mathrm{ml} \mathrm{PBS}$ ) were 10-fold diluted in SIBA lysis/reaction buffer and analysed with the SARS-CoV-2 RT-SIBA assay. Only $1 / 128(0,7 \%)$ of the 10 -fold diluted negative oropharyngeal swabs showed non-target amplification, with a very small amplification curve (Fig. 3e). These results show that samples must be diluted 10-fold in SIBA lysis/reaction buffer before being analysed on the Egoo device. To methodologically simplify the dilution procedure for non-professionals, $10 \mathrm{ml}$ of SIBA lysis/reaction buffer must be added to a sample collection tube if the sample is to be used directly in the SARS-CoV-2 RT-SIBA assay on the Egoo device (Fig. 3f).

\section{Compatibility to sample media}

Since samples must be diluted 10 -fold to reduce non-target amplification in the oropharyngeal swab we wanted to investigate whether other sampling media such as UTM and VTM can be used with the Egoo Health System. We also tested different media used for antigen quick tests. We simulated SARS-CoV-2 positive samples by spiking SARS-CoV-2 virus culture (Hong Kong/VM2000i06i/2020 or (USAWA1/2020)) into PBS, UTM (Copan), VTM (NEST Biotechnology), VTM (Mole Bioscience), Gensure antigen buffer (Gensure), Acro antigen buffer (ACRO), BIOSYNEX antigen buffer (BIOSYNEX) or Biosensor antigen buffer (SD Biosensor) (1:10). The simulated samples were further diluted 10-fold in SIBA lysis/reaction buffer before the samples were analysed with the SARS-CoV-2 RT-SIBA assay on the Egoo instrument (Fig. 4). The SARS-CoV-2 RT-SIBA assay was not influenced by the presence of UTM (Copan), VTM (NEST Biotechnology), VTM (Mole Bioscience), and all dilutions of the virus culture (Fig. 4a-b) were detected except the SARS-CoV-2 negative samples (Fig. 4g). In addition, we observed no difference between SARS-CoV-2 positive samples dissolved in PBS and Acro antigen buffer (ACRO), BIOSYNEX antigen buffer (BIOSYNEX) or Biosensor antigen buffer (SD Biosensor) (Fig. 4d-f). However, SARS-CoV-2 positive samples dissolved in Gensure antigen buffer (Gensure) were inhibited (Fig. 4c). These results show that the SARS-CoV-2 RT-SIBA assay is dependent on the sample collection media and only the above-mentioned medias have been validated for the SARS-CoV-2 RT-SIBA assay. Figure $4 \mathrm{~h}$ shows an overview of the SARS-CoV-2 RT-SIBA assay when using other sampling media.

\section{Comparison to reference RT-PCR assays and platforms}


The direct lysis and 10-fold dilution of the sample could potentially result in a lower clinical sensitivity of the SARS-CoV-2 RT-SIBA assay. To test this, the performance of the SARS-CoV-2 RT-SIBA assay on the Egoo instrument was tested on patient samples diagnosed positive or negative for SARS-CoV-2 using different RT-PCR platforms. Two of the studies were performed independently at two different Danish hospitals. In total 1154 patient samples were tested with the Egoo Health system and compared to either; 1) direct lysis using SIBA lysis/reagent buffer (no NA purification) followed by RT-PCR for the E-gene 31 (Qlife COVID-19 Service Center), 2) the SARS-CoV-2 Roche Flow/MGI-BGI RT-PCR assay (Hvidovre and Amager hospitals), 3) The Cobas SARS-CoV-2 \& Influenza A/B Nucleic acid test on the Cobas Liat System (Nordsjællands hospital). The comparison study showed a clinical sensitivity between $87.8-98.4 \%$ (Table 5). Dividing the patient samples into groups based on the ct-values from the RT-PCR analysis we find a sensitivity of the SARS-CoV-2 RT-SIBA assay in the Egoo instrument for samples with ct-values $\leq 35, \leq 36$, $\leq 37, \leq 38$ range from $98.4 \%$ (95\% Cl: $94.3-99.8), 97.5 \%$ (95\%Cl: $93.3-99.5)$ to $96.5 \%$ (95\%Cl: $91.2-88.5)$ respectively for the direct lysis RT-PCR method and from $96.6 \%$ (95\%Cl: $94.5-98.0), 95.9 \%$ (95\%Cl: $93.7-$ 97.5), $94.7 \%$ (95\%Cl:92.4-96.5) to $93.8 \%$ (95\%Cl: 91.4-95.8) respectively for the Roche Flow/MGI-BGI RTPCR assay. The Cobas LIAT System does not return results as ct-values and therefore the division of the samples based on ct-values can not be performed for the Cobas LIAT comparison study. These results show that a 10-fold dilution of the sample in SIBA/reaction buffer will result in a lower clinical sensitivity compared to standard RT-PCR methods, however only samples with very high ct-values will not be detected with the SARS-CoV-2 RT-SIBA assay on the Egoo instrument.

The specificity of the SARS-CoV-2 RT-SIBA assay in the Egoo instrument ranged from 96.6-98.2\% (Table 5) showing that the 10-fold dilution of the sample in SIBA lysis/reaction buffer significantly reduces the non-target amplification of the SYBR based assay. The results were obtained using the Clinical app, but if we evaluate the results by the slope of the amplification curves of the true positives and false positives, the big comparison study $(n=1154)$ showed a clear difference in the slope of the curves (Supplementary Figure S1) which could indicate that adjustments to the current algorithm could increase the specificity of the SARS-CoV-2 RT-SIBA assay on the Egoo instrument to $98.2-100 \%$.

\section{Discussion}

Here, we present for the first time a very compact instrument called the Egoo Health System, which has been developed for home-use monitoring of biochemical markers. The Egoo Health System is simple to use and can be used in private homes, primary care clinics, nursing homes, and workplaces without the need for specialized laboratory staff.

The Egoo Health system uses specialized Egoo capsules that are sealed in the Egoo instrument with a piston mechanism and a plunger. Once the plunger has sealed the capsule tight, the reaction begins which eliminates the risk of amplicon contamination. The amplification steps in NAAT tests are extreme, resulting in billions of copies of the target of interest. This amplification step requires a closed system to avoid amplicon contamination and the detection of false positives. Opening a tube after an amplification to use it on a lateral flow stick ${ }^{19,34}$ is possible to do in a specialised laboratory but is not possible to do 
outside a laboratory in the current form without a high risk of contaminating the surroundings and the following patient samples. Recently alternatives to the lateral flow sticks have been developed e.g. the Lucira $^{\text {TM }}$ COVID-19 All-in-One single-use Test kit (https://www.lucirahealth.com/) and the single-use COVID-19 test from Visby medical (https://www.visbymedical.com/) which are all-in-one single use NAAT tests that eliminates the need for opening the tube after amplification. In contrast to these single-use molecular test kits, the Egoo instrument can be used unlimited times and only requires replacing the assay capsule after use. Therefore, the Egoo Health System can be used for many subsequent assays, including tests for other respiratory viruses and biochemical markers such C-reactive protein (CRP) and Phenylalanine (PHE) (https://www.egoo.health).

Due to limiting heating capacity of the small Egoo instrument, we developed an isothermal SARS-CoV-2 assay based on RT-SIBA ${ }^{28,29}$ and SYBR green detection. The SARS-CoV-2 RT-SIBA reaction can be performed at $40-44^{\circ} \mathrm{C}$ and can be used in both the Egoo instrument and in high-throughput format using PCR instruments. The gold standard RT-PCR test is dependent on the heating and cooling of the sample for the amplification reaction to occur. Heating and cooling require specialized equipment and so far, the most common PCR instruments have been too big and heavy to handle outside the laboratory. Recently, the CovidNudge portable RT-PCR platform ${ }^{27}$ and the single-use RT-PCR device from Visby medical 26 were developed which opens the possibility to perform the gold standard RT-PCR outside the laboratory. The Egoo instrument uses similar fluorescence optics as a PCR instrument and as such we observe a similar performance of the SARS-CoV-2 RT-SIBA assay in the two instruments with an analytical sensitivity of 25 viral RNA copies per reaction.

For methodological simplicity, we developed an extraction-free SARS-CoV-2 RT-SIBA assay that uses a specialized SIBA lysis/reaction buffer containing mild detergents. During the COVID-19 pandemic, NA extraction has proved not only to be time-consuming, and has caused bottlenecks due to lack/shortage of consumables. Therefore, many laboratories have been forced to look for alternative methods to NA extraction such as direct use of the crude sample using either heat or detergents for inactivation and lysis of the virus. This has proven to be almost as sensitive and specific as the gold standard purification methods ${ }^{5-7,9,35}$ and after optimization, we ended with a simplified sampling workflow for the SARS-CoV2 RT-SIBA assay that can be used with the Egoo instrument.

When performing the SARS-CoV-2 RT-SIBA assay in a PCR instrument a melting curve analysis can be performed to test the specificity of the assay. However, this is not possible in the Egoo instrument and therefore sample dilution must be performed to reduce non-target amplification, e.g., by adding a high sampling volume $(10 \mathrm{ml})$ to the collection tube or diluting the sample 10-fold. Studies have shown that direct use of nasopharyngeal or oropharyngeal samples dissolved in PBS, Saline, and UTM without NA extraction can inhibit direct RT-PCR ${ }^{9,35}$ and dilution of samples (or reducing the sample input volume into the RT-PCR reaction) reduced the inhibitory effect ${ }^{35}$. The 10 -fold dilution of the sample before analysis in the Egoo instrument will therefore not only eliminate non-target amplification but may also eliminate inhibitors that might otherwise influence the SARS-CoV-2 RT-SIBA reaction. Another advantage of the 
dilution workflow is that the SARS-CoV-2 RT-SIBA assay is compatible with several different VTMs, UTMs and antigen buffer systems. We show that SARS-CoV-2 RT-SIBA assay on the Egoo Health System is compatible with several of the widely used antigen buffers systems and therefore can be used as a confirmatory NAAT test of patients tested positive or negative with a rapid antigen test ${ }^{4}$.

The SARS-CoV-2 RT-SIBA assay on the Egoo Health system showed a sensitivity between 87.0-94.7\% dependent on the reference NAAT test used. We obtained the lowest sensitivity of $87.0 \%(100 / 115)$ when the assay was compared to the Cobas SARS-CoV-2 \& Influenza A/B NAAT test on the Cobas Liat System. The main reason for this difference is the sample input volume into the system. For the Corbas Liat system $200 \mu \mathrm{l}$ sample is loaded directly into the assay cartridge, whereas for the Egoo system $20 \mu \mathrm{l}$ sample is 10 -fold diluted before $20 \mu \mathrm{l}$ of the diluted sample is loaded into the Egoo capsule, meaning that there is a 100-fold difference in sample input between the two systems. Compared to the Roche Flow/MGI-BGI RT-PCR reference method which include a NA purification, an up concentration (180 $\mu$ l to $33 \mu \mathrm{l})$ of the RNA and detection of two targets, we obtained a sensitivity of $91.8 \%(482 / 525)$ with the Egoo Health system. For samples with ct-values below 35 the Egoo system achieved a sensitivity of $96.6 \%$ (450/466) meaning that samples with low viral load (high ct-values) could potentially not be detected with the Egoo Health system.

The clinical performance of the SARS-CoV-2 RT-SIBA assay on the Egoo Health system is similar to the clinical performance of the COVID-19 test on the Cue Health Monitoring system ${ }^{25}$. The Cue Health Monitoring System (Cue Cartridge Reader) have recently developed a COVID-19 Test Cartridge which was evaluated on 292 symptomatic and asymptomatic patients ${ }^{25}$. They showed a positive percent agreement (PPA) of $91.7 \%$ (22/24) and a negative percent agreement (NPA) of 98.4\% (239/243) compared to a reference NAAT test using standard nasopharyngeal swab ${ }^{25}$ which is comparable to our sensitivity and specificity of $91.8 \%$ and $98.2 \%$ respectively when testing 1154 oropharyngeal swabs.

The Egoo Health System and SARS-CoV-2 RT-SIBA assay presented here has recently been CE-marked for professional use (Qlife), and we are currently trying to develop a multiplex probe based SARS-CoV-2 RT-

SIBA assay containing the human RNaseP as an internal control ${ }^{36,37}$ that can be used directly on anterior nasal swabs.

\section{Declarations}

\section{Data availability}

Data sharing not applicable to this article as no datasets were generated.

\section{Acknowledgements}

We would like to thank Susanne Lopez Rasmussen, Louise Borup, Dennis Jelsbak Schmidt and Birgit Knudsen for technical assistance and Anne Mette Edeltoft for the graphic designs and illustrations of the figures. We also would like to thank Georg Parsons for his editorial comments. 
MWR, SJ, ETD, HW, DML, JB, JH, LJ, JB, CP, CJJ, FHJ, UVS, JGL, RLJ performed the experiments. AB, SC, FH designed the software for the Egoo Health System, TO, AT, MB developed the SIBA reagents and edited the manuscript. TW, EF, PW, LB, RE, MBD, MRJ, JWL designed, developed, and build the Egoo Health System including Egoo analysis capsules, MWR wrote the manuscript. AF, CJJ, FHJ, UVS, JGL, RLJ, EF, ETD, KC, JBL, CP and HW edited the manuscript. All authors discussed the results and commented on the manuscript.

\section{Additional Information}

\section{Competing interests}

All authors employed at Qlife Aps and Aidian declare a financial competing interest.

All authors employed at SSI, Hvidovre and Amager hospital and Nordsjællands hospital declare no competing interests.

\section{References}

1. WHO. Coronavirus disease 2019 (COVID-19) - situation report 51. (2020).

2. Kwon, K. T., Ko, J. H., Shin, H., Sung, M. \& Kim, J. Y. Drive-through screening center for covid-19: A safe and efficient screening system against massive community outbreak. J. Korean Med. Sci, 35, 25 (2020).

3. Mark, K. et al. Coronavirus disease (COVID-19) community testing team in Scotland: A 14-day review, 6 to 20 February 2020. Eurosurveillance, 25, 1-6 (2020).

4. Peeling, R. W., Olliaro, P. L., Boeras, D. I. \& Fongwen, N. Scaling up COVID-19 rapid antigen tests: promises and challenges. Lancet Infect. Dis, 3099, 21-26 (2021).

5. Fomsgaard, A. S. \& Rosenstierne, M. W. An alternative workflow for molecular detection of SARSCoV-2 - Escape from the NA extraction kit-shortage, Copenhagen, Denmark, March 2020. Eurosurveillance, 25, 1-4 (2020).

6. Jørgensen, R. L. et al. An in-well direct lysis method for rapid detection of SARS-CoV-2 by real time RT-PCR in eSwab specimens. J. Virol. Methods, 289, 2020-2022 (2021).

7. Lalli, M. et al. Rapid and extraction-free detection of SARS-CoV-2 from saliva with colorimetric LAMP. Clin. Chem, https://doi.org/10.1101/2020.05.07.20093542 (2020).

8. Esbin, M. N. et al. Overcoming the bottleneck to widespread testing: A rapid review of nucleic acid testing approaches for COVID-19 detection., 26, 771-783 (2020).

9. Calvez, R., Taylor, A., Calvo-Bado, L., Fraser, D. \& Fink, C. G. Molecular detection of SARS-CoV-2 using a reagent-free approach. PLoS One, 15, 1-11 (2020). 
10. Kitagawa, Y. et al. Evaluation of rapid diagnosis of novel coronavirus disease (COVID-19) using loopmediated isothermal amplification. J. Clin. Virol, 129, 104446 (2020).

11. Lamb, L. E., Bartolone, S. N., Ward, E. \& Chancellor, M. B. Rapid detection of novel coronavirus/Severe Acute Respiratory Syndrome Coronavirus 2 (SARS-CoV-2) by reverse transcription-loop-mediated isothermal amplification. PLoS One, 15, 1-15 (2020).

12. Lu, R. et al. A novel reverse transcription loop-mediated isothermal amplification method for rapid detection of sars-cov-2.Int. J. Mol. Sci.21, (2020).

13. Park, G. S. et al. Development of Reverse Transcription Loop-Mediated Isothermal Amplification Assays Targeting Severe Acute Respiratory Syndrome Coronavirus 2 (SARS-CoV-2). J. Mol. Diagnostics, 22, 729-735 (2020).

14. Ganguli, A. et al. Rapid isothermal amplification and portable detection system for SARS-CoV-2. Proc. Natl. Acad. Sci. U. S. A. 117, 22727-22735(2020).

15. Yan, C. et al. Rapid and visual detection of 2019 novel coronavirus (SARS-CoV-2) by a reverse transcription loop-mediated isothermal amplification assay. Clin. Microbiol. Infect, 26, 773-779 (2020).

16. Baek, Y. H. et al. Development of a reverse transcription-loop-mediated isothermal amplification as a rapid early-detection method for novel SARS-CoV-2. Emerg. Microbes Infect, 9, 998-1007 (2020).

17. Cui, Z. et al. Development of a rapid test kit for SARS-CoV-2: an example of product design. BioDesign Manuf, 3, 83-86 (2020).

18. Fozouni, P. et al. Amplification-free detection of SARS-CoV-2 with CRISPR-Cas13a and mobile phone microscopy., 184, 323-3339 (2021).

19. Broughton, J. P. et al. CRISPR-Cas12-based detection of SARS-CoV-2. Nat. Biotechnol, 38, 870-874 (2020).

20. Behrmann, O. et al. Rapid Detection of SARS-CoV-2 by Low Volume Real-Time Single Tube Reverse Transcription Recombinase Polymerase Amplification Using an Exo Probe with an Internally Linked Quencher (Exo-IQ). Clin. Chem, 66, 1047-1054 (2020).

21. Xia, S. \& Chen, X. Single-copy sensitive, field-deployable, and simultaneous dual-gene detection of SARS-CoV-2 RNA via modified RT-RPA. Cell Discov, 6, 4-7 (2020).

22. Huang, W. et al. The determination of release from isolation of COVID-19 patients requires ultra-high sensitivity nucleic acid test technology. J. Infect, 82, 159-198 (2021).

23. Basu, A. et al. Performance of abbott id now covid-19 rapid nucleic acid amplification test using nasopharyngeal swabs transported in viral transport media and dry nasal swabs in a New York city academic institution. J. Clin. Microbiol.58, (2020).

24. Harrington, A. et al. Comparison of abbott id now and abbott m2000 methods for the detection of sars-cov-2 from nasopharyngeal and nasal swabs from symptomatic patients. J. Clin. Microbiol, 58, $1-3(2020)$. 
25. Donato, L. J. et al. Evaluation of the Cue Health point-of-care COVID-19 (SARS-CoV-2 nucleic acid amplification) test at a community drive through collection center. Diagn. Microbiol. Infect. Dis, 100, 2019-2022 (2021).

26. Renzoni, A. et al. Analytical Evaluation of Visby Medical RT-PCR Portable Device for Rapid Detection of SARS-CoV-2. Diagnostics, 11, 813 (2021).

27. Gibani, M. M. et al. Assessing a novel, lab-free, point-of-care test for SARS-CoV-2 (CovidNudge): a diagnostic accuracy study. The Lancet Microbe, 1, e300-e307 (2020).

28. Hoser, M. J., Mansukoski, H. K., Morrical, S. W. \& Eboigbodin, K. E. Strand Invasion Based Amplification (SIBA $\AA$ ): A novel isothermal DNA amplification technology demonstrating high specificity and sensitivity for a single molecule of target analyte. PLOS One, 9, 1-20 (2014).

29. Eboigbodin, K. et al. Reverse transcription strand invasion based amplification (RT-SIBA): a method for rapid detection of influenza A and B. Appl. Microbiol. Biotechnol, 100, 5559-5567 (2016).

30. MOEMS: Micro-Opto-Electro-Mechanical Systems. (SPIE).

31. Corman, V. M. et al. Detection of 2019 novel coronavirus (2019-nCoV) by real-time RTPCR. Eurosurveillance25, (2020).

32. Li, D., Zhang, J. \& Li, J. Primer design for quantitative real-time PCR for the emerging Coronavirus SARS-CoV-2. Theranostics, 10, 7150-7162 (2020).

33. Shu, Y. \& McCauley, J. G. I. S. A. I. D. Global initiative on sharing all influenza data - from vision to reality. Eurosurveillance, 22, 2-4 (2017).

34. Santiago, I. Trends and Innovations in Biosensors for COVID-19 Mass Testing. ChemBioChem 21, 2880-2889(2020).

35. Smyrlaki, I. et al. Massive and rapid COVID-19 testing is feasible by extraction-free SARS-CoV-2 RTPCR. Nat. Commun, 11, 1-12 (2020).

36. Eboigbodin, K. E. \& Hoser, M. J. Multiplex Strand Invasion Based Amplification (mSIBA) assay for detection of Chlamydia trachomatis and Neisseria gonorrhoeae. Sci. Rep, 6, 1-9 (2016).

37. Eboigbodin, K. E., Moilanen, K., Elf, S. \& Hoser, M. Rapid and sensitive real-time assay for the detection of respiratory syncytial virus using RT-SIBA®. BMC Infect. Dis, 17, 1-7 (2017).

\section{Tables}

\section{Table 1: Egoo device fact box}




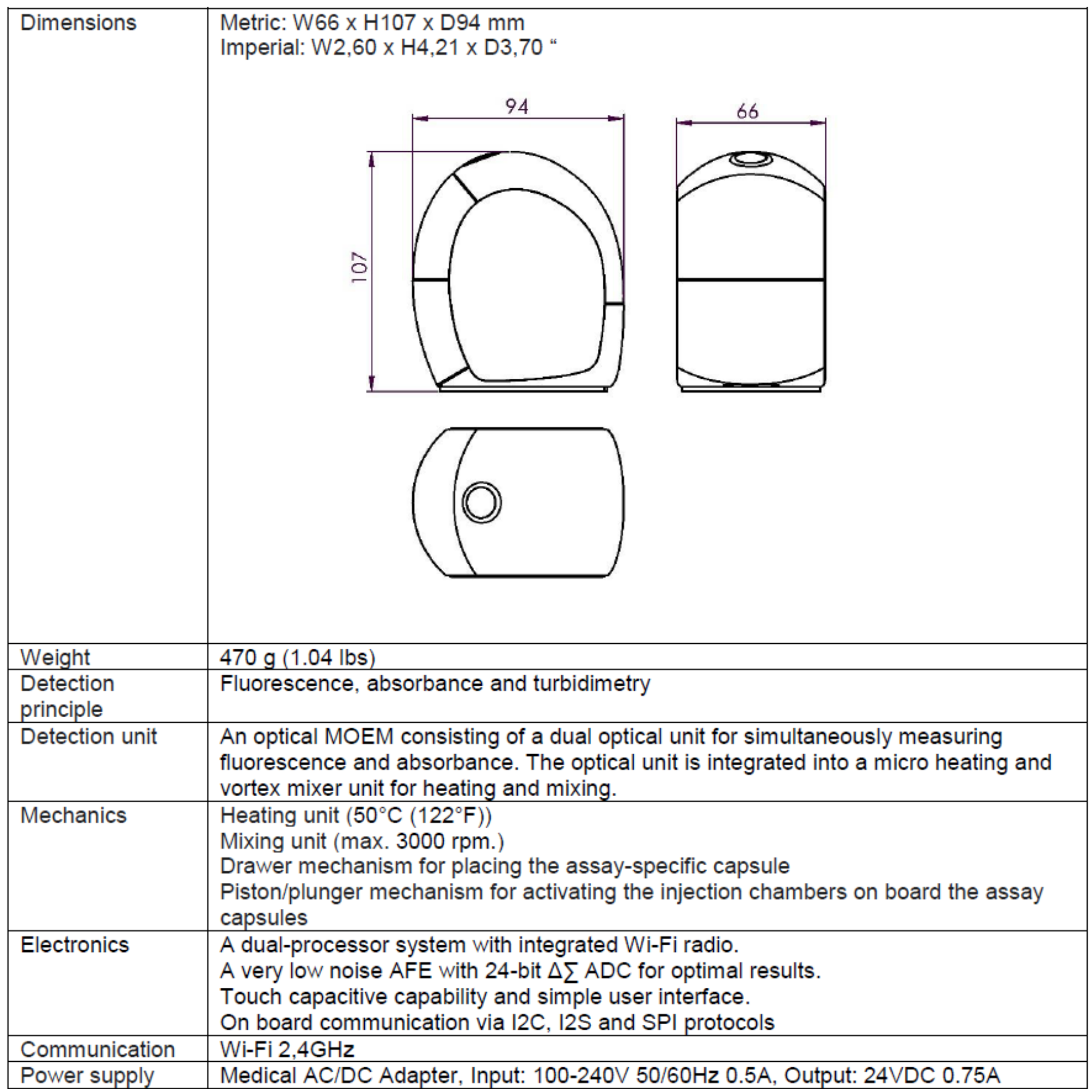

Table 2: Sars-CoV-2 RT-SIBA assay capsule fact box 


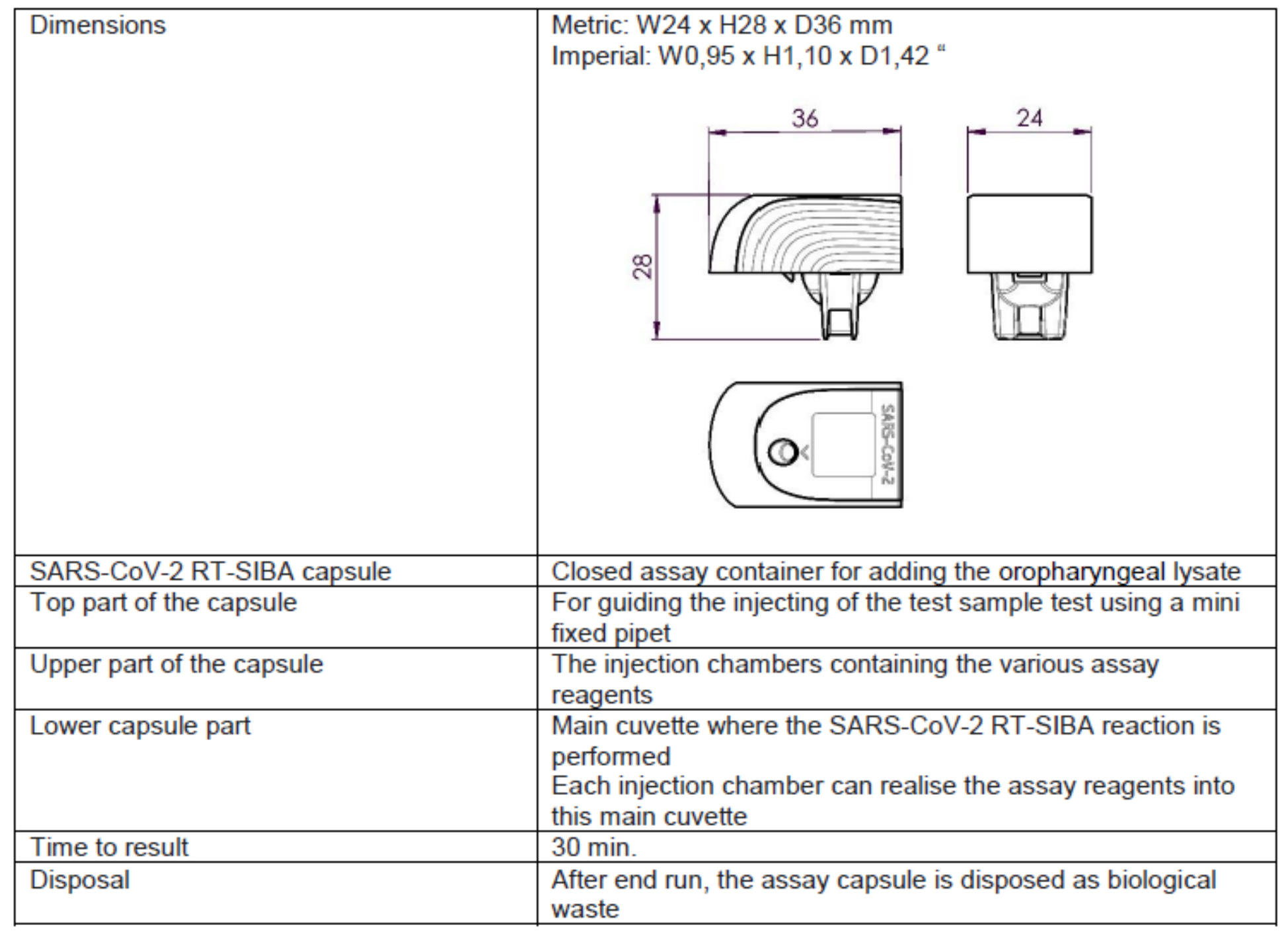

Table 3: Analytical specificity of the SARS-CoV-2 RT SIBA assay 
PCR

Egoo

instrument ${ }^{1,2}$

instrument

\section{Purified NA}

\begin{tabular}{lll} 
hCoV-NL63 & $0 / 4^{1}$ & na \\
\hline hCoV-OC43 & $0 / 3^{1}$ & na \\
\hline hCoV-229E & $0 / 1^{1}$ & na \\
\hline hCoV-HKU1 & $0 / 1^{1}$ & na \\
\hline MERS & $0 / 5^{1}$ & na
\end{tabular}

Virus culture spiked into oropharyngeal swab (non-purified NA)

\begin{tabular}{lll} 
hCoV-NL63 & $0 / 5^{2}$ & $0 / 5$ \\
\hline hCoV-229E & $0 / 5^{2}$ & $0 / 5$ \\
\hline RSV & $0 / 8^{2}$ & $0 / 5$ \\
\hline hMPV & $0 / 8^{2}$ & $0 / 5$ \\
\hline EBV & $0 / 5^{2}$ & $0 / 5$ \\
\hline PIV-1 & $0 / 5^{2}$ & $0 / 5$ \\
\hline ADV5 & $0 / 5^{2}$ & $0 / 5$ \\
\hline INFL A & $0 / 5^{2}$ & $0 / 5$ \\
H1N1pdm & & $0 / 5$ \\
\hline INFL B & $0 / 5^{2}$ & $0 / 5$ \\
\hline Enterovirus & $0 / 5^{2}$ & $5 / 5$ \\
68 & & \\
\hline SARS-CoV-2 & $5 / 5^{2}$ & \\
\hline
\end{tabular}

NA: nucleic acids, INFL: Influenza virus, pdm: 2009 pandemic, RSV: Respiratory Syncytial Virus, hCoV: Human Corona virus, MERS: Middel East Respiratory syndrome relates coronavirus, hMPV: Human Metapneumovirus, EBV: Epstein Barr virus, PIV-1: Parainfluenza virus type 1, ADV5: adenovirus type 5, na: not analyzed

${ }^{1} \mathrm{MX3005P}$ (Strategene)

${ }^{2}$ CFX96dx (BioRAD) 
Sample material

on PCR instrument ${ }^{1}$
SARS-COV-2 RT-SIBA

on Egoo device

$\begin{array}{llllllll}\begin{array}{l}\text { Viral } \\ \text { load } \\ (\mathrm{cp} / \mu \mathrm{l})\end{array} & \begin{array}{l}\text { Copies to RT- } \\ \text { SIBA }\end{array} & \begin{array}{l}\text { No. } \\ \text { of }\end{array} & \begin{array}{l}\text { Min. } \\ \text { to }\end{array} & \begin{array}{l}\text { Viral } \\ \text { load } \\ \text { pos. }\end{array} & \begin{array}{l}\text { Copies to } \\ \text { RT-SIBA } \\ \text { react) }\end{array} & \begin{array}{l}\text { No. } \\ \text { of }\end{array} & \begin{array}{l}\text { Min. } \\ \text { to } \\ \text { pos. }\end{array} \\ & & \text { Pos. } & \text { pos. } & & & \text { Pos. } & \end{array}$

(\%) (mean

\pm SD)

(\%) (mean

\begin{tabular}{|c|c|c|c|c|c|c|c|c|}
\hline \multirow[t]{8}{*}{$\begin{array}{l}\text { Synthetic } \\
\text { RNA }^{2}\end{array}$} & $1.0 \times 10^{5}$ & $2.5 \times 10^{5}$ & $\begin{array}{l}6 / 6 \\
(100)\end{array}$ & $\begin{array}{l}8.5 \pm \\
0.5\end{array}$ & $1.0 \times 10^{5}$ & $2.0 \times 10^{6}$ & $\begin{array}{l}8 / 8 \\
(100)\end{array}$ & $\begin{array}{l}16.0 \pm \\
1.5\end{array}$ \\
\hline & $1.0 \times 10^{4}$ & $2.5 \times 10^{4}$ & $\begin{array}{l}6 / 6 \\
(100)\end{array}$ & $\begin{array}{l}9.6 \pm \\
0.1\end{array}$ & $1.0 \times 10^{4}$ & $2.0 \times 10^{5}$ & $\begin{array}{l}6 / 6 \\
(100)\end{array}$ & $\begin{array}{l}16.7 \pm \\
2.1\end{array}$ \\
\hline & $1.0 \times 10^{3}$ & $2.5 \times 10^{3}$ & $\begin{array}{l}6 / 6 \\
(100)\end{array}$ & $\begin{array}{l}10.3 \pm \\
0.4\end{array}$ & $1.0 \times 10^{3}$ & $2.0 \times 10^{4}$ & $\begin{array}{l}6 / 6 \\
(100)\end{array}$ & $\begin{array}{l}17.2 \pm \\
1.7\end{array}$ \\
\hline & $1.0 \times 10^{2}$ & $2.5 \times 10^{2}$ & $\begin{array}{l}6 / 6 \\
(100)\end{array}$ & $\begin{array}{l}11.7 \pm \\
0.5\end{array}$ & $1.0 \times 10^{2}$ & $2.0 \times 10^{3}$ & $\begin{array}{l}6 / 6 \\
(100)\end{array}$ & $\begin{array}{l}19.8 \pm \\
2.3\end{array}$ \\
\hline & $1.0 \times 10^{1}$ & $2.5 \times 10^{1}$ & $\begin{array}{l}6 / 6 \\
(100)\end{array}$ & $\begin{array}{l}14.3 \pm \\
1.1\end{array}$ & $1.0 \times 10^{1}$ & $2.0 \times 10^{2}$ & $\begin{array}{l}6 / 6 \\
(100)\end{array}$ & $\begin{array}{l}21.5 \pm \\
3.3\end{array}$ \\
\hline & $1.0 \times 10^{0}$ & $2.5 \times 10^{0}$ & $\begin{array}{l}5 / 6 \\
(83)\end{array}$ & $\begin{array}{l}16.9 \pm \\
0.9\end{array}$ & $1.0 \times 10^{0}$ & $2.0 \times 10^{1}$ & $\begin{array}{l}7 / 7 \\
(100)\end{array}$ & $\begin{array}{l}25.6 \pm \\
3.3\end{array}$ \\
\hline & $1.0 \times 10^{-1}$ & $2.5 \times 10^{-1}$ & na & na & $1.0 \times 10^{-1}$ & $2.0 \times 10^{0}$ & $\begin{array}{l}1 / 8 \\
(13)\end{array}$ & 22.9 \\
\hline & 0 & 0 & $0 / 6$ & 0 & 0 & 0 & $0 / 6$ & 0 \\
\hline \multirow[t]{7}{*}{$\begin{array}{l}\text { Virus } \\
\text { culture }^{3}\end{array}$} & $1.2 \times 10^{3}$ & $2.9 \times 10^{3}$ & $\begin{array}{l}64 / 64 \\
(100)\end{array}$ & $\begin{array}{l}12.6 \pm \\
1.1\end{array}$ & $1.2 \times 10^{3}$ & $2.4 \times 10^{3}$ & $\begin{array}{l}2 / 2 \\
(100)\end{array}$ & $\begin{array}{l}16.3 \pm \\
0.7\end{array}$ \\
\hline & $1.2 \times 10^{2}$ & $2.9 \times 10^{2}$ & $\begin{array}{l}64 / 64 \\
(100)\end{array}$ & $\begin{array}{l}15.9 \pm \\
1.9\end{array}$ & $1.2 \times 10^{2}$ & $2.4 \times 10^{2}$ & $\begin{array}{l}1 / 1 \\
(100)\end{array}$ & 21.88 \\
\hline & $1.0 \times 10^{1}$ & $2.6 \times 10^{1}$ & $\begin{array}{l}33 / 33 \\
(100)\end{array}$ & $\begin{array}{l}20.8 \pm \\
3.0\end{array}$ & $1.2 \times 10^{1}$ & $1.0 \times 10^{2}$ & $\begin{array}{l}2 / 2 \\
(100)\end{array}$ & $\begin{array}{l}21.4 \pm \\
0.7\end{array}$ \\
\hline & $9.3 \times 10^{0}$ & $2.3 \times 10^{1}$ & $\begin{array}{l}32 / 33 \\
(97)\end{array}$ & $\begin{array}{l}19.9 \pm \\
2.2^{2}\end{array}$ & $6 \times 10^{0}$ & $5.0 \times 10^{1}$ & $\begin{array}{l}2 / 2 \\
(100)\end{array}$ & $\begin{array}{l}21.9 \pm \\
1.4\end{array}$ \\
\hline & $8.1 \times 10^{0}$ & $2.0 \times 10^{1}$ & $\begin{array}{l}33 / 33 \\
(100)\end{array}$ & $\begin{array}{l}20.1 \pm \\
1.8\end{array}$ & $1.3 \times 10^{0}$ & $2.5 \times 10^{1}$ & $\begin{array}{l}19 / 20 \\
(95)\end{array}$ & $\begin{array}{l}21.8 \pm \\
1.8\end{array}$ \\
\hline & $6.3 \times 10^{0}$ & $1.6 \times 10^{1}$ & $\begin{array}{l}31 / 33 \\
(94)\end{array}$ & $\begin{array}{l}21.9 \pm \\
3.9\end{array}$ & $1 \times 10^{0}$ & $2.0 \times 10^{1}$ & $\begin{array}{l}9 / 20 \\
(45)\end{array}$ & $\begin{array}{l}23.9 \pm \\
2.9\end{array}$ \\
\hline & 0 & 0 & $0 / 33$ & 0 & 0 & 0 & $0 / 6$ & 0 \\
\hline
\end{tabular}

na; not analyzed, no; number, Pos; positive, min; minutes, SD; standard deviation, the bold highlights define the limit of detection. 
${ }^{1} \mathrm{MX} 3005 \mathrm{P}$

2 Twistsyntetic SARS-COV-2 RNA ctr1

${ }^{3}$ 2019-nCoV isolate (026V-03883) (EVAg)

Table 5: The clinical sensitivity and specificity of the SARS-CoV-2 RT-SIBA assay on the Egoo instrument compared to different RT-PCR platforms ( $n=1154)$

\begin{tabular}{|c|c|c|c|c|c|c|c|}
\hline $\begin{array}{l}\text { NA and RT- } \\
\text { PCR } \\
\text { platform }\end{array}$ & Material & $\begin{array}{l}\text { CT- } \\
\text { values }\end{array}$ & $\begin{array}{l}\mathrm{N} \\
\text { (pos/neg) }\end{array}$ & $\begin{array}{l}\text { Sensitivity } \\
\text { (\%) }\end{array}$ & $\begin{array}{l}95 \% \mathrm{Cl} \\
(\%)\end{array}$ & $\begin{array}{l}\text { Specificity } \\
(\%)\end{array}$ & $\begin{array}{l}95 \% \mathrm{Cl} \\
(\%)\end{array}$ \\
\hline \multirow{5}{*}{$\begin{array}{l}\text { Direct lysis } \\
\text { and RT- } \\
\text { PCR }^{1}\end{array}$} & \multirow[t]{5}{*}{$\begin{array}{l}\text { Oropharyngeal } \\
\text { swab in PBS }\end{array}$} & $\leq 45$ & \multirow[t]{5}{*}{$\begin{array}{l}230 \\
(132 / 98)\end{array}$} & 94.7 & $\begin{array}{l}90.4- \\
98.3\end{array}$ & \multirow[t]{5}{*}{$96.9-100 *$} & \multirow[t]{5}{*}{$\begin{array}{l}91.3- \\
99.4\end{array}$} \\
\hline & & $\leq 38$ & & 94.7 & $\begin{array}{l}90.4- \\
98.3\end{array}$ & & \\
\hline & & $\leq 37$ & & 96.5 & $\begin{array}{l}91.2- \\
98.7\end{array}$ & & \\
\hline & & $\leq 36$ & & 97.6 & $\begin{array}{l}93.3- \\
99.5\end{array}$ & & \\
\hline & & $\leq 35$ & & 98.4 & $\begin{array}{l}94.3- \\
99.8\end{array}$ & & \\
\hline \multirow{5}{*}{$\begin{array}{l}\text { Roche } \\
\text { Flow/MGI- } \\
\text { BGI RT- } \\
\text { PCR }^{2}\end{array}$} & \multirow[t]{5}{*}{$\begin{array}{l}\text { Oropharyngeal } \\
\text { swab in UTM }\end{array}$} & $\leq 45$ & \multirow[t]{5}{*}{$\begin{array}{l}700 \\
(525 / 98)\end{array}$} & 91.8 & $\begin{array}{l}89.1- \\
94.0\end{array}$ & \multirow[t]{5}{*}{$\begin{array}{l}96.6- \\
100.0^{*}\end{array}$} & \multirow[t]{5}{*}{$\begin{array}{l}92.7- \\
98.7\end{array}$} \\
\hline & & $\leq 38$ & & 93.8 & $\begin{array}{l}91.4- \\
95.8\end{array}$ & & \\
\hline & & $\leq 37$ & & 94.7 & $\begin{array}{l}92.4- \\
96.5\end{array}$ & & \\
\hline & & $\leq 36$ & & 95.9 & $\begin{array}{l}93.7- \\
97.5\end{array}$ & & \\
\hline & & $\leq 35$ & & 96.6 & $\begin{array}{l}94.5- \\
98.0\end{array}$ & & \\
\hline $\begin{array}{l}\text { Cobas LIAT } \\
\text { System }^{3}\end{array}$ & $\begin{array}{l}\text { Oropharyngeal } \\
\text { swab in UTM }\end{array}$ & $\mathrm{N} / \mathrm{A}$ & $\begin{array}{l}224 \\
(115 / 109)\end{array}$ & 87.0 & $\begin{array}{l}79.4- \\
92.5\end{array}$ & 98.2 & $\begin{array}{l}93.5- \\
99.8\end{array}$ \\
\hline
\end{tabular}

NA, Nucleic acids; OP, oropharyngeal swab; PBS, Phosphate-buffered saline, UTM, universal transport medium; $\mathrm{Cl}$, confidence interval.

${ }^{1}$ diagnosed with direct lysis using SIBA lysis/reaction buffer and the RT-PCR for the E-gene ${ }^{31}$

${ }^{2}$ diagnosed with the Cobas SARS-CoV-2 \& Influenza A/B NAAT test 
${ }^{3}$ diagnose with the SARS-CoV-2 Roche Flow/MGI-BGI RT-PCR

*based on evaluation of the curves and not the Clinical app.

Figures

a

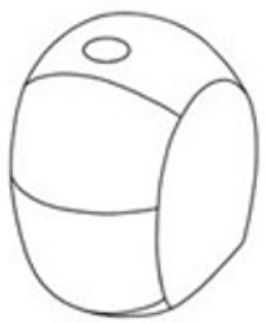

c

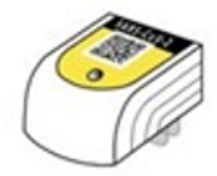

b

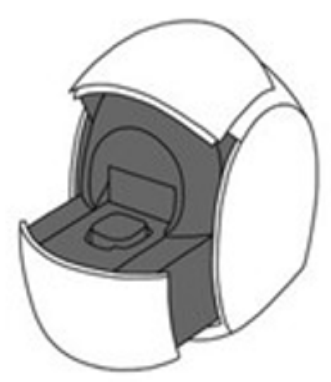

d

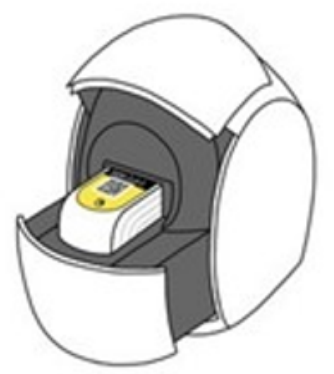

e

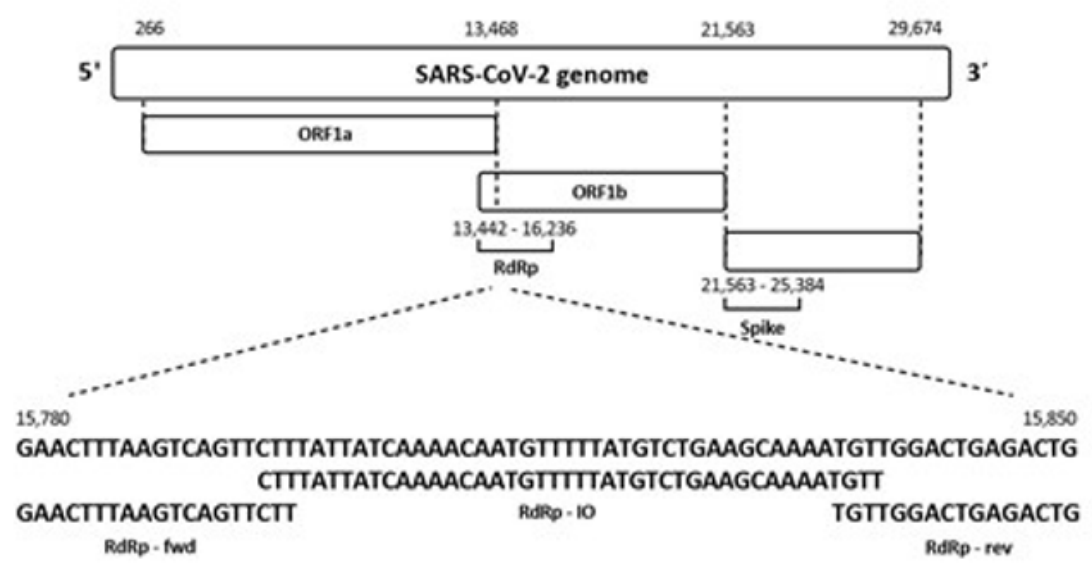

f

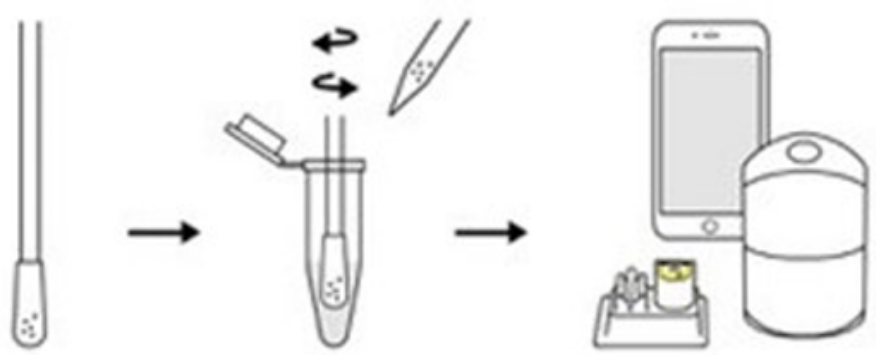

Figure 1 
The Egoo Health System and the SARS-CoV-2 RT-SIBA assay. a) the Egoo instrument in the closed position. b) the Egoo instrument in the open position. c) the SARS-CoV-2 RT-SIBA capsule. d) the SARSCoV-2 RT-SIBA capsule placed into the Egoo instrument. e) The SARS-CoV-2 genome with the RdRp gene and the position of the SARS-CoV-2 RT-SIBA assay is shown with the sequence of the invasion oligo (RdRp IO) and the forward (RdRp-fwd) and reverse (RdRp-rev) primer. f) The sampling workflow for the SARS-CoV-2 RT-SIBA assay. The swab is directly dissolved in SIBA lysis/reaction buffer and $20 \mu \mathrm{l}$ of the sample is transferred to the SARS-CoV-2 RT-SIBA capsule and analysed in the Egoo instrument.

a

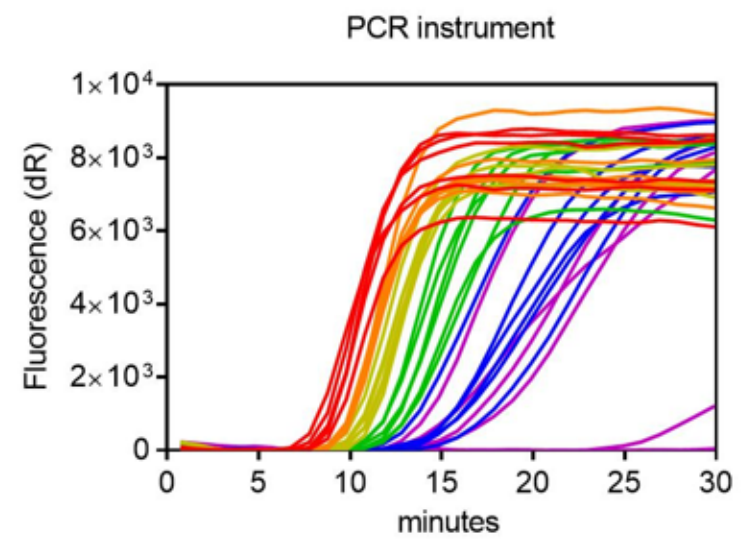

b

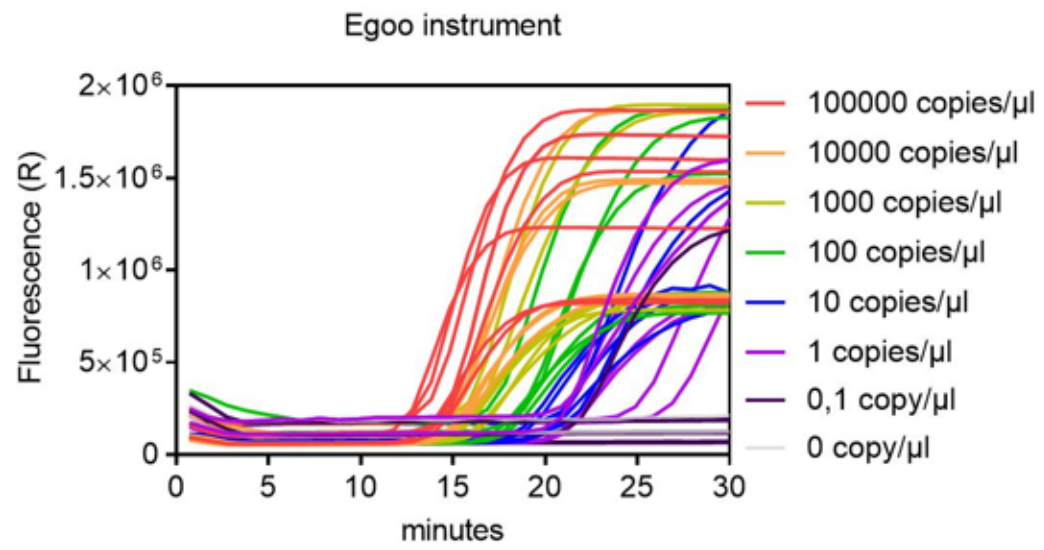

Figure 2

The analytical sensitivity of the SARS-CoV-2 RT-SIBA assay. Amplification curves of synthetic SARS-CoV2 RNA diluted in negative oropharyngeal swab dissolved in SIBA lysis/reaction buffer and analysed in the a) MX3005P PCR instrument $(n=6)$ or in b) five different non-calibrated Egoo instruments $(n=6)$. The different concentrations (RNA copies/ $\mu$ l) of synthetic RNA are color coated on both graphs. 
a

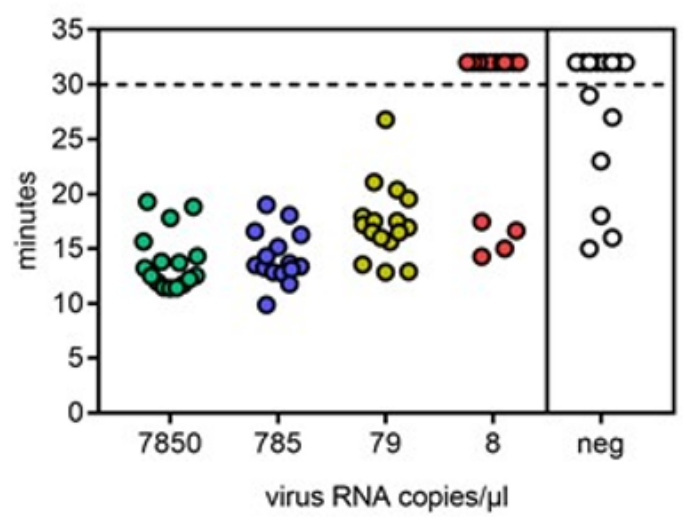

C

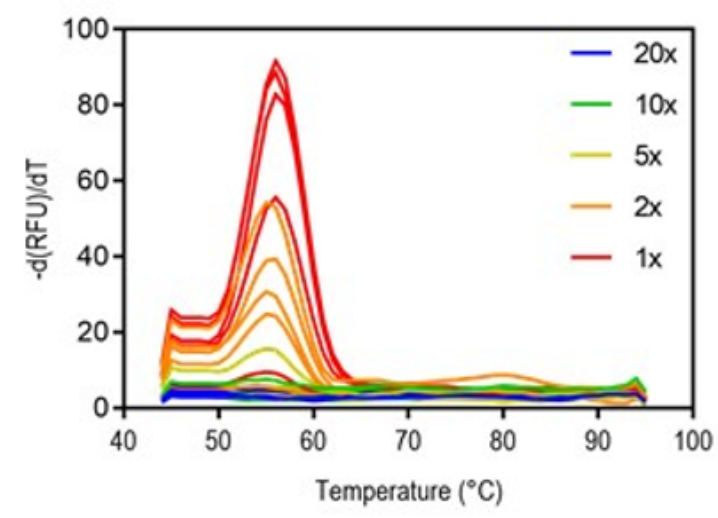

e

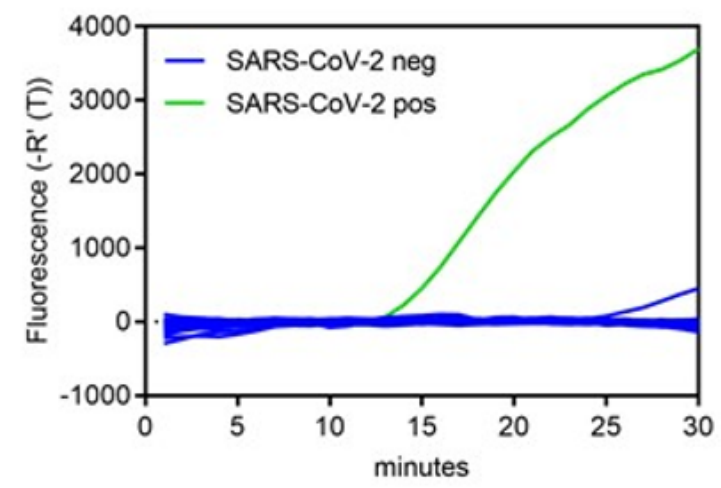

b

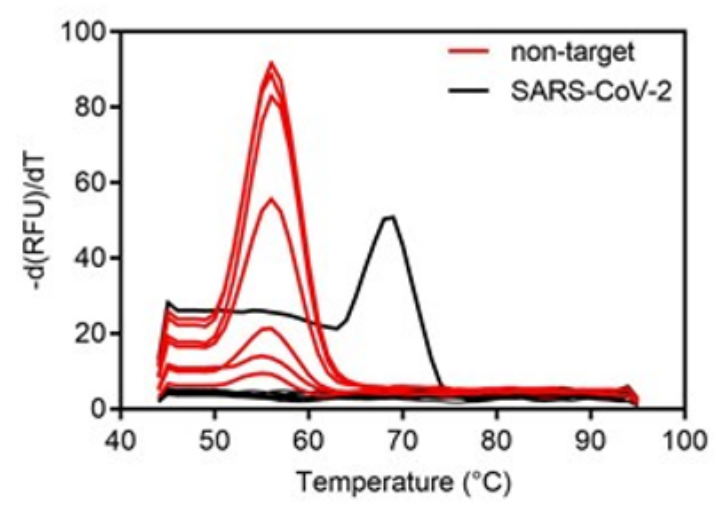

d

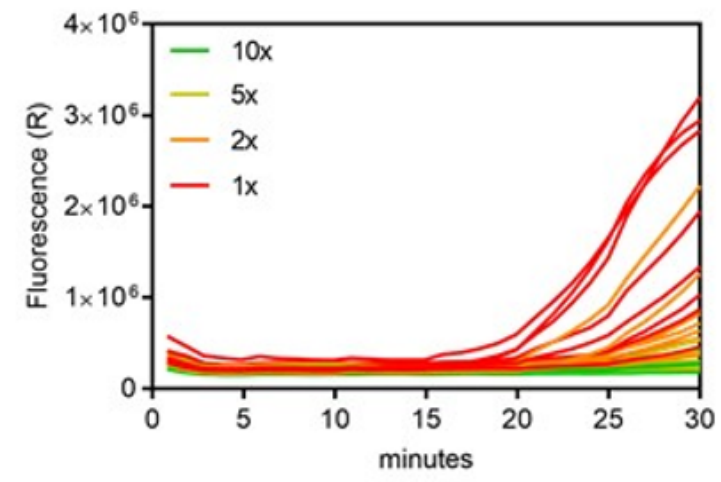

f

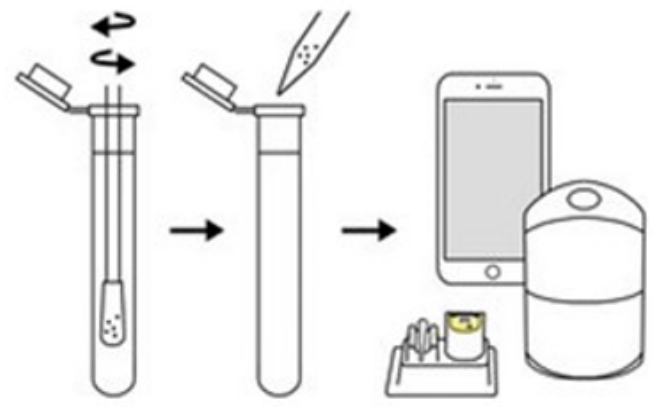

\section{Figure 3}

The sampling method for the SARS-CoV-2 RT-SIBA assay. a) Analysis of SARS-CoV-2 spiked swabs dissolved directly in SIBA lysis/reaction buffer and analysed with the SARS-CoV-2 RT-SIBA assay in a PCR instrument (MX3005P). The graph shows time to positive in minutes and the calculated hypothetical virus concentration (virus RNA copies/ $\mu$ l) of the sample after the swab has been dissolved in $500 \mu$ SIBA lysis/reaction buffer $(n=16)$. For graphical appearance samples that are not detected are given the 
hypothetical value of 32 minutes which is shown above the final reaction time (30 minutes) (dotted line). b) Melting curve analysis of the false positive (non-target) signal detected in the negative oropharyngeal swabs. The melting peak for a true positive signal (black) is shown $\left(68^{\circ} \mathrm{C}\right)$ and the melting peak for the false positives (non-target) (red) $\left(56^{\circ} \mathrm{C}\right)$ is shown. c) Melting peaks from different dilutions of the falsepositive samples. The melting peak from the different dilutions $(1 \mathrm{x}, 2 \mathrm{x}, 5 \mathrm{x}, 10 \mathrm{x}$, and $20 \mathrm{x})$ are color coated. d) Analysis of false positive samples in the Egoo instrument. The amplification curves from the different dilutions (1x, 2x, 5x, and 10x) are color coated. e) Analysis of negative oropharyngeal swabs diluted 10fold in SIBA lysis/reaction buffer ( $n=128)$. Amplification curves from the SARS-CoV-2 positive control (green) and the negative oropharyngeal swabs (blue) are shown. f) The sampling workflow for the SARSCoV-2 RT-SIBA assay. The swab is directly dissolved in $10 \mathrm{ml}$ SIBA lysis/reaction buffer and $20 \mu \mathrm{l}$ is transferred to the SARS-CoV-2 RT-SIBA capsule and analysed in the Egoo instrument.

a

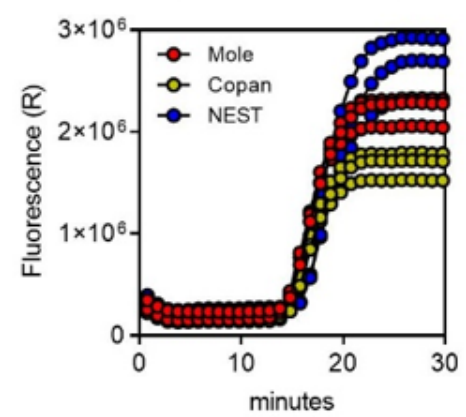

Transport medie

b

b

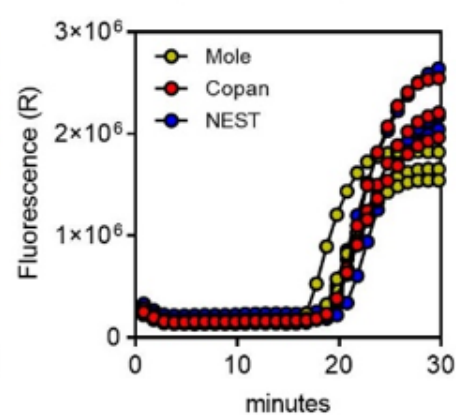

Transport media
$\left(1.15 \times 10^{1} \mathrm{TCID}_{50} / \mathrm{ml}\right)$

c

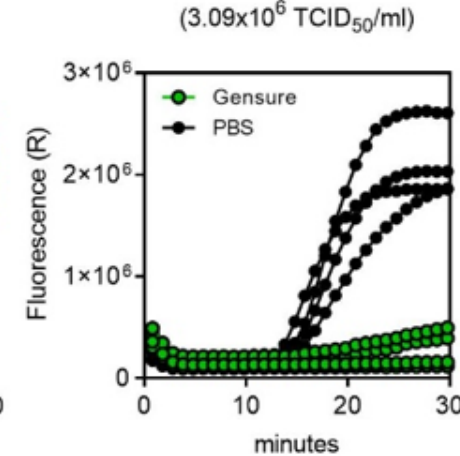

g (3.09x $\left.10^{6} \mathrm{TCID}_{50} / \mathrm{ml}\right)$

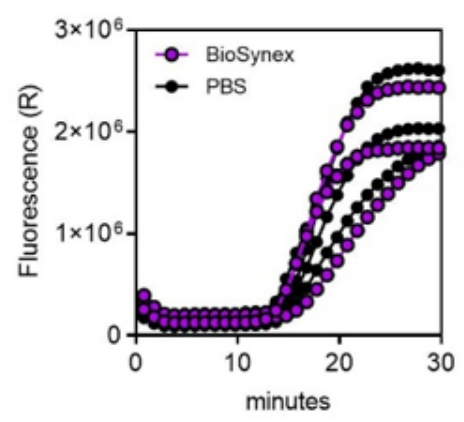
$\left(3.09 \times 10^{6} \mathrm{TCID} / \mathrm{ml}\right)$

f

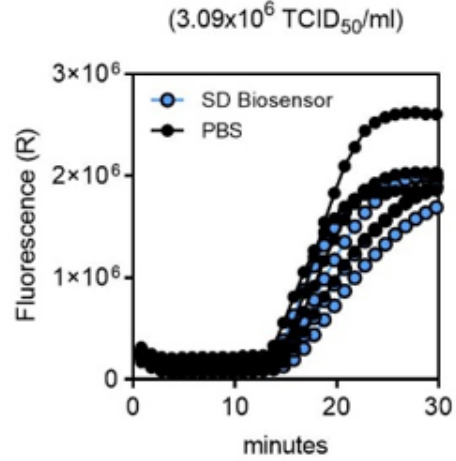

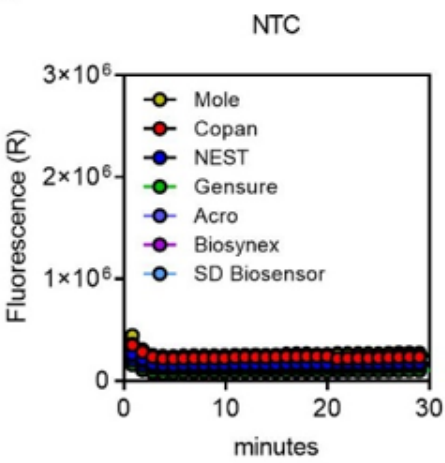

d

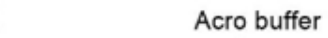
(3.09 $\times 10^{6} \mathrm{TCID}_{50} / \mathrm{ml}$ )

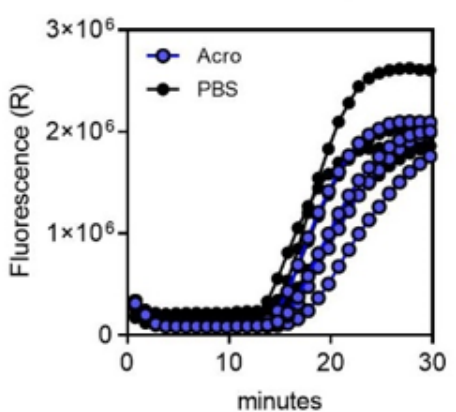

h

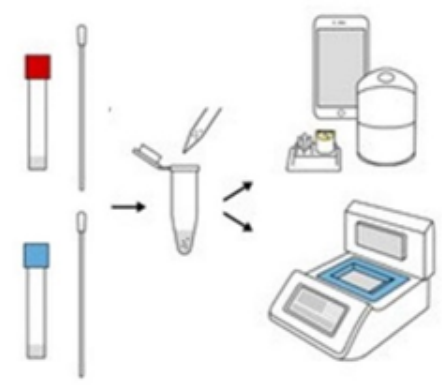

Figure 4

Analysis of the SARS-CoV-2 RT-SIBA assay in the Egoo Health System using different sampling medium. a-b) Amplification curves for two dilutions of the SARS-CoV-2 virus isolate (Hong Kong VM20001061/2020) in different transport medium (UTM (Copan), VTM (Mole and NEST) (n=3). c-f) Amplification curves for the SARS-CoV-2 virus isolate (USA-WA1/2020) dissolved in different antigen test sampling medium (GenSureTM COVID-19 Antigen Rapid Test, ACRO Rapid Test, BIOSYNEX®COVID-19 Ag BSS, COVID-19 Ag (SD Biosensor)) ( $n=4)$. g) Amplification curves for negative control (NTC) samples dissolved in the different transport medium and antigen sampling buffers $(n=3)$. $h)$ The sampling workflow for the SARS-CoV-2 RT-SIBA assay when using different sampling medium. The swab is directly 
dissolved in $1 \mathrm{ml}$ of medium/buffer and $20 \mu \mathrm{l}$ is transferred to a dilution tube containing $180 \mu \mathrm{I}$ SIBA lysis/reaction buffer. The sample is mixed by pipetting up and down multiple times and $20 \mu \mathrm{l}$ is transferred to the SARS-CoV-2 RT-SIBA capsule and analysed in the Egoo device.

\section{Supplementary Files}

This is a list of supplementary files associated with this preprint. Click to download.

- Supplementaryinformation2021SR.pdf 